\title{
SIMULASI PENERAPAN TEORI ANTRIAN DALAM PEMBATASAN PENGUNJUNG OBJEK WISATA
}

\section{Application of Queuing Theory on Visitor Restrictions of Tourism Places}

\author{
Ezra Putranda Setiawan ${ }^{1 *}$, Heru Sukoco ${ }^{2}$, Lusi Harini ${ }^{3}$ \\ 1,2,3 Jurusan Pendidikan Matematika, Fakultas MIPA, Universitas Negeri Yogyakarta \\ Jln. Colombo 1, Caturtunggal, Depok, Sleman, Indonesia
}

Corresponding author's e-mail: 1* ezra.ps@uny.ac.id

\begin{abstract}
Abstrak
Pembatasan jumlah pengunjung objek wisata merupakan salah satu mekanisme pelaksanaan protokol kesehatan selama masa normal baru (new normal). Pembatasan ini kadangkala menjadi dilema, mengingat pengelola objek wisata ingin memaksimumkan pendapatan dari para pengunjung sementara kapasitas tempat wisata sengaja dibatasi. Di sisi lain, penentuan banyaknya pengunjung objek wisata secara real time tidak mudah dilakukan mengingat pengunjung dapat keluar masuk kapan saja. Dalam penelitian ini, teori antrian (queueing theory) akan dipergunakan untuk menyelesaikan permasalahan tersebut. Pengunjung objek wisata dianggap sebagai pengantri, sedangkan lama kunjungan dari kedatangan hingga kepulangan dari objek wisata dipandang sebagai lama proses pelayanan. Dengan mengestimasi rata-rata lama kunjungan dan mengukur laju kedatangan pengunjung, banyaknya orang yang berada di dalam obek wisata dapat dihitung sebagai jumlah orang di dalam sistem. Sebagai suatu studi pendahuluan, dalam penelitian ini hanya dibahas aplikasi model antrian M/M/1 dan M/G/1. Studi lebih lanjut perlu dilakukan untuk mengembangkan model serta mengkalibrasi model dengan data dari objek wisata tertentu.
\end{abstract}

Kata Kunci : Teori antrian, wisatawan, kapasitas, objek wisata, penerapan.

\begin{abstract}
Restrictions of the visitor on the tourism places is one of the mechanism of health protocol that carried out during the new normal era. This restriction become a dilemma since the manager of the tourism places want to maximize their profit by allowing all visitor, while the government still limiting the number of visitor to avoid crowding. Otherwise, real-time monitoring of the number of visitor somewhat difficult since they can come in and leave the tourism places at any time. In this study we implement the queuing theory to solve this problem. The visitor of the tourism places is modelled as the customer, while the time spent by them in the tourism places is modelled as the serving duration. By estimating the average of time spent by the visitor and determine the average number of arrivals during the specified time, the number of visitor in the tourism place can be estimated as the number of people in the queuing system. As a preliminary study, this paper only focused on two queuing model, namely the $M / M / 1$ and $M / G / 1$. Further study is needed to develop the model and calibrate it using the data from a specified tourism place.
\end{abstract}

Keywords: Queuing theory, tourist, capacity, tourism places, application 


\section{PENDAHULUAN}

Bulan Maret 2020, masyarakat di seluruh dunia dihadapkan pada masalah pandemi yang disebabkan oleh Coronavirus Disease (Covid). Penyakit ini menyerang sistem pernapasan manusia dan bahkan dapat menyebabkan kematian. Penularan penyakit ini juga sangat cepat karena dapat berlangsung lewat udara (airborne). Oleh karena itu, pandemi Covid-19 menimbulkan dampak besar bagi sistem pendidikan yang ditandai dengan penghentian kegiatan tatap muka secara fisik di sekolah-sekolah di seluruh dunia [1]-[3]. Pandemi Covid-19 juga berdampak pada pengurangan aktivitas di luar rumah, melambatnya kegiatan ekonomi di berbagai sektor, serta meningkatnya pengangguran [4].

Indonesia merupakan salah satu negara yang terkenal dengan pariwisata. Telah jamak diketahui bahwa terdapat banyak objek wisata di Indonesia, mulai dari Danau Toba, Candi Borobudur, Pulau Bali, Gili Trawangan, Labuan Bajo, Wakatobi, hingga Raja Ampat. Sebelum pandemi Covid-19 melanda, industri pariwisata merupakan salah satu pasar terbesar dunia [5]. Pada tahun 2019, lebih dari 1,2 juta wisatawan dari berbagai negara berkunjung ke Indonesia setiap bulannya. Data tersebut akan semakin banyak bila ditambah dengan wisatawan lokal, termasuk di antaranya rombongan pelajar yang melakukan study tour ke berbagai daerah di Indonesia.

Tingginya jumlah korban Covid-19 di berbagai daerah di Inodnesia memaksa Pemerintah Pusat maupun Pemerintah Daerah memberlakukan Pembatasan Sosial Berskala Besar (PSBB) pada tahun 2020, yang diikuti dengan Pemberlakuan Pembatasan Kegiatan Masyarakat (PPKM). Berdasarkan Instruksi Menteri Dalam Negeri Republik Indonesia nomor 14 Tahun 2021, dilakukan pembatasan kegiatan pada area publik, termasuk objek wisata. Objek wisata di Kabupaten/kota selain zona merah diizinkan dibuka dengan pembatasan kapasitas maksimal 25\%, sementara pada kabupaten/kota yang termasuk zona merah ditutup. Pembatasan ini menyebabkan sektor pariwisata sangat rentan terdampak [6]-[8] dibandingkan sektor ekonomi lainnya. Sebagai contoh, jumlah wisatawan asing yang berkunjung ke Indonesia pada Maret 2021 turun 71,84\% dibandingkan Maret 2020 [9]. Hal ini tentu saja menimbulkan dampak pada pihak-pihak yang terkait dengan jasa pariwisata, misalnya pengelola objek wisata, perhotelan, biro jasa perjalanan, pemandu wisata, dan sebagainya.

Menghadapi situasi tersebut, diperlukan dukungan dari berbagai pihak agar sektor pariwisata dapat kembali pulih. Adaptasi kondisi normal baru di sektor pariwisata perlu didukung dengan penerapan regulasi dan penegakan hukum yang ketat, pengembangan pariwisata digital, pengenalan tren pariwisata baru dan kolaborasi antar pemangku kepentingan [10]. Dapat pula dibuat rancang bangun aplikasi sistem informasi pariwisata berbasis android didalamnya terdapat sekumpulan data industri pariwisata yang menyediakan data SDM pariwisata, jenis jasa, daya tarik, dan sarana wisata yang tersebar di Indonesia [11].

Salah satu permasalahan dalam pengembangan tempat wisata dapat disebabkan oleh adanya aturan pembatasan jumlah pengunjung. Di satu sisi, pengelola tempat wisata diwajibkan mencegah terjadinya kerumunan dengan menjaga agar jumlah pengunjung tidak melebihi batas yang ditentukan. Sebaliknya, melakukan penolakan pengunjung akan menurunkan potensi pendapatan pengelola wisata. Di sisi lain, melakukan pengamatan secara terus menerus pada pintu masuk dan pintu keluar untuk menjaga 'kapasitas' tempat wisata akan memunculkan kebutuhan tenaga baru. Pemasangan mekanisme pintu masuk dan pintu keluar yang dapat 'mencacah' jumlah individu pun tidak mudah dilakukan. Demikian pula mekanisme 'buka tutup' pintu masuk objek wisata berpotensi merugikan wisatawan dari segi waktu.

Teori antrian (queuing theory) pada dasarnya merupakan pendekatan matematis [12], dikenal sebagai bagian dari riset operasi [13]. Antrian dicirikan oleh kedatangan dan proses layanan, jumlah server, dan kedisiplinan layanan [14]. Selain itu, antrian juga terkait dengan slotted service systems yang memungkinkan konsumen atau pengunjung untuk datang kembali [15].

Dalam penelitian ini akan ditinjau penerapan teori antrian dalam pemodelan jumlah pengunjung tempat wisata. Secara khusus, tempat wisata yang dimaksud adalah tempat wisata yang terbuka dan luas, misalnya tempat wisata alam, candi, dan sebagainya. Pada tempat-tempat wisata tersebut, jumlah maksimum pengunjung sebenarnya dapat dipandang sebagai suatu angka yang fleksibel karena tidak ada ukuran yang jelas seperti kapasitas ttempat duduk dan sebagainya. Dengan didasarkan pada teori antrian, riset ini menyajikan suatu mekanisme yang relatif praktis untuk melakukan pembatasan jumlah pengunjung sembari mengurangi kemungkinan terjadinya "penolakan" pengunjung. 


\section{METODE PENELITIAN}

Dalam bagian ini akan disajikan konsep-konsep dasar teori antrian serta proses pengembangan model berdasarkan teori tersebut.

\subsection{Teori Antrian}

Antrian adalah suatu garis tunggu dari orang/satuan yang memerlukan pelayanan dari satu atau lebih fasilitas layanan [16]. Sebagai contoh, antrian dapat dijumpai pada kendaraan yang hendak memasuki tol, pada caloncalon penumpang kereta api yang akan memasuki peron, pasien yang hendak memasuki layanan rumah sakit, hingga barang-barang yang hendak dikirimkan di suatu kantor ekspedisi. Antrian merupakan bagian yang penting dari manajemen operasi baik di sektor jasa mapupun industri [17].

Komponen utama suatu proses antrian [18], [19] adalah sebagai berikut:

a. Proses Kedatangan

Proses kedatangan menunjuk pada aturan kedatangan pelanggan ke sistem antrian. Antrian akan terbentuk bila banyaknya pelanggan yang datang melebihi kapasitas pelayanan. Proses kedatangan umumnya dideskripsikan oleh waktu antar kedatangan (interarrival times). Dalam model-model yang lebih kompleks, dianalisis pula apakah pelanggan datang satu per satu atau berombongan, apakah terdapat pembatalan dan penolakan, dan sebagainya.

b. Proses Pelayanan

Proses pelayanan dianalisis melalui banyaknya pelayan serta waktu pelayanan (service time), yakni waktu yang dibutuhkan seorang pelayan untuk melayani satu pelanggan.

c. Kapasitas Sistem

Kapasitas sistem adalah jumlah maksimum pelanggan, baik yang sedang dilayani maupun yang sedang berada di dalam antrian. Kapasitas suatu sistem dapat mencapai tak berhingga, yakni pada sistem yang tidak membatasi jumlah pelanggan di dalamnya.

d. Populasi

Populasi atau disbut juga sumber pemanggilan merupakan banyaknya pelanggan potensial yang dapat memasuki sistem.

e. Disiplin Antrian

Disiplin antrian merupakan ketentuan cara pelayanan pelanggan dalam antrian. Pada umumnya digunakan aturan pertama masuk pertama keluar (first in first out, disingkat FIFO). Dalam literatur, dikenal pula beberapa macam disiplin antrian, misalnya antrian dalam urutan acak, pelanggan terakhir dilayani lebih awal, adanya kelas prioritas, dan sebagainya.

Mengacu pada [18], model antrian sering dinyatakan dalam notasi Kendall yang berbentuk $a / b / c / d / e$, dengan $a$ menyatakan pola kedatangan $(\mathrm{M}=$ Markovian, $\mathrm{G}=$ general $), b$ menyatakan pola pelayanan, $c$ menunjukkan jumlah pelayan yang ada, $d$ menyatakan kapasitas sistem, dan $e$ menyatakan disiplin antrian. Bila $d$ dan e tidak ditentukan, dimaksudkan bahwa kapasitas sistem adalah tak berhingga dan disiplin antrian adalah pertama masuk pertama dilayani.

\subsection{Teknik Pengumpulan Data dan Analisis Data}

Dalam penelitian ini, proses pengumpulan dan analisis data dilakukan dalam dua tahap, yakni sintesis atau pengembangan model dan simulasi. Pengembangan model dilakukan dengan meninjau perbandingan antara sistem antrian dan sistem kunjungan pada objek wisata, kemudian diidentifikasi model antrian yang tepat untuk menggambarkan sistem tersebut. Simulasi merupakan sebuah model dengan berisikan variabel yang menampilkan ciri utama dari sistem kehidupan yang sebenarnya [20].Simulasi dilakukan pada model antrian yang telah dipilih guna memperjelas karakteristik daripada sistem antrian tersebut.

\section{HASIL DAN PEMBAHASAN}

Dalam bab ini akan ditinjau kembali model antrian dengan satu pelayan. Selanjutnya, disajikan bentuk implementasi teori antrian guna memodelkan pengunjung objek wisata serta simulasinya. Objek wisata yang dimaksud adalah objek wisata yang relatif luas dan kapasitasnya tidak ditentukan berdasar suatu unit terhitung (misal 'tempat duduk' atau 'meja'). 


\subsection{Model Antrian Satu Pelayan}

Suatu proses antrian melibatkan kedatangan pelanggan pada suatu fasilitas pelayanan dengan pola tertentu. Pelanggan tersebut akan menunggu dalam suatu antrian bila seluruh pelayannya sibuk. Dengan demikian, proses antrian dapat dipandang sebagai suatu proses kelahiran-kematian (birth-death process). Kelahiran terjadi bila pelanggan tiba di fasilitas pelayanan, dan kematian terjadi bila pelanggan meninggalkan fasilitas pelayanan tersebut. Dengan mengetahui distribusi atau pola waktu antar-kedatangan dan waktu antar pelayanan, dapat diduga banyaknya orang yang menunggu dalam antrian, banyaknya orang yang berada dalam sistem, lama waktu tunggu antrian, lama waktu di dalam sistem, hingga efisiensi antrian.

Dalam suatu sistem antrian dengan pelayan tunggal, misal diketahui bahwa waktu antar kedatangan berdistribusi eksponensial dengan rata-rata $1 / \lambda$, dan waktu/lama pelayanan berdistribusi eksponensial dengan rata-rata $1 / \mu$. Antrian jenis ini dapat ditulis dalam notasi Kendall sebagai M/M/1. Selanjutnya dapat diperoleh rata-rata waktu yang dihabiskan pelanggan dalam sistem [21] adalah

$$
W=\frac{1}{\mu-\lambda}
$$

dan rata-rata banyaknya pelanggan dalam sistem adalah

$$
L=\frac{(\lambda / \mu)}{1-(\lambda / \mu)}
$$

Bila dilakukan generalisasi dengan meniadakan asumsi distribusi eksponensial pada lama pelayanan, akan diperoleh model M/G/1. Pada model ini, hubungan (1) dan (2) di atas tidak berlaku. Sebagai gantinya, dapat dipergunakan model Pollaczek-Khintchine [21] sebagai berikut. Bila lama pelayanan memiliki ratarata sebesar $\mathrm{E}(t)$ dan variansi $\operatorname{var}(t)$, maka berlaku

$$
L=\lambda E(t)+\frac{\lambda^{2}\left(E^{2}(t)+\operatorname{var}(t)\right)}{2(1-\lambda E(t))}, \lambda E(t)<1
$$

dan

$$
W=\frac{1}{E(t)}+E(t)+\frac{\lambda\left(E^{2}(t)+\operatorname{var}(t)\right)}{2(1-\lambda E(t))}, \lambda E(t)<1
$$

Apabila waktu antar kedatangan pelanggan juga tidak berdistribusi eksponensial, maka nilai L dan $\mathrm{W}$ hanya dapat ditentukan melalui simulasi (Taha, 2017).

\subsection{Implementasi Model Antrian pada Tempat Wisata}

Selanjutnya pandang sebuah tempat wisata dengan kapasitas tertentu, namakan $N$. Laju kedatangan pengunjung ke tempat wisata tersebut, yakni banyaknya pengunjung yang datang setiap satuan waktu, dapat ditentukan dengan melakukan pengamatan di pintu masuk tempat wisata. Dengan cara yang sama, dapat dilakukan estimasi laju kepulangan, yakni banyaknya pengunjung yang meninggalkan tempat wisata setiap satuan waktu. Analog dengan sistem antrian, laju kepulangan dapat dipandang sebagai laju pelayanan, karena pelanggan pada sistem antrian akan meninggalkan antrian setelah pelayanan selesai dilakukan. Dengan cara ini, rata-rata banyaknya pelanggan dalam sistem dapat dipandang sebagai dugaan untuk banyaknya orang yang berada di tempat wisata tersebut. Pembatasan jumlah pengunjung tempat wisata dapat dilakukan dengan memastikan bahwa $L<N$.

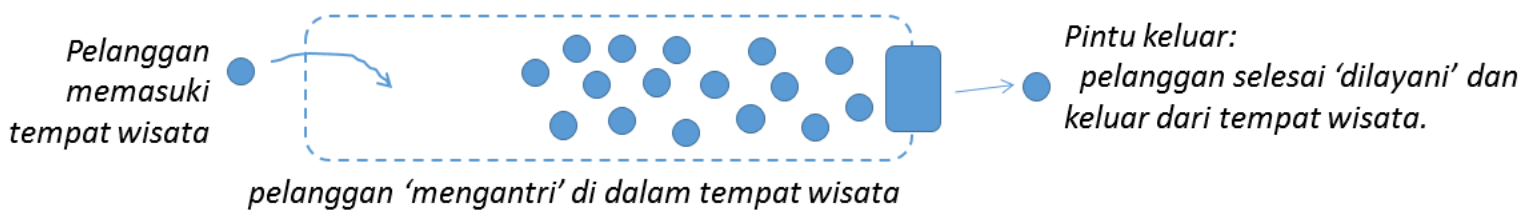

Gambar 1. Ilustrasi cara kerja model antrian pada tempat wisata 


\section{Contoh 1.}

Misalkan kapasitas maksimal suatu tempat wisata dengan pemberlakuan protokol kesehatan adalah sebanyak 300 pengunjung. Dari serangkaian pengamatan, diketahui bahwa rata-rata banyaknya pengunjung yang meninggalkan tempat wisata tersebut dalam 10 menit adalah 25 orang. Dengan demikian, didapat $\mu=2,5$. Bila dalam satu jam terdapat 120 pengunjung yang memasuki tempat wisata $(\lambda=2)$, akan diperoleh nilai $L$ $=4$ orang. Selanjutnya, bila dalam satu jam terdapat 135 pengunjung yang memasuki tempat wisata $(\lambda=$ 2,25), akan diperoleh nilai $L=9$ orang. Dari model ini terlihat bahwa semakin banyak jumlah pengunjung yang datang dalam satu jamnya, semakin banyak pula orang yang berada di tempat wisata.

Apakah model di atas layak digunakan? Diperhatikan bahwa pada saat laju kedatangan pengunjung adalah 120 orang/jam, rata-rata lama di sistem adalah sebesar 2 menit, sedangkan pada saat laju kedatangan meningkat menjadi 200 orang/jam, rata-rata lama di sistem adalah sebesar 4 menit. Hal ini menjadi tidak masuk akal, mengingat pada umumnya orang ingin menghabiskan waktu yang relatif lama di tempat wisata. Selain itu, laju kepulangan pengunjung dari suatu tempat wisata dalam satu hari tidaklah konstan. Untuk tempat wisata yang buka pada pagi hingga sore hari, misalnya, laju kepulangan pengunjung di pagi hari tentu jauh lebih rendah dibandingkan laju kepulangan pada sore hari saat tempat wisata tersebut hendak ditutup. Terakhir, tidak logis bila terdapat 105 pengunjung yang memasuki tempat wisata dalam satu jam namun terdapat 150 pengunjung yang meninggalkan tempat tersebut dalam satu jam. Demikian pula sangat tidak logis bahwa hanya ada 4 sampai 9 orang dalam suatu objek wisata pada saat kunjungannya ramai.

Untuk mengatasi permasalahan tersebut, implementasi model antrian di atas harus dimodifikasi dengan memberikan 'kesempatan' bagi laju kepulangan pengunjung untuk berubah-ubah nilainya. Hal ini masuk akal, mengingat seseorang cenderung mempercepat kunjungannya di suatu tempat wisata bila tempat tersebut terlalu ramai. Cara termudah adalah dengan 'mengunci' rata-rata lama pengunjung berada di tempat wisata, yang ekuivalen dengan rata-rata lama seseorang berada dalam sistem antrian $W$.

Di bawah asumsi bahwa waktu antar kedatangan dan waktu antar kepulangan pengunjung berdistribusi eksponensial, hal ini dapat dilakukan sebagai berikut. Dari persamaan (1), terlihat bahwa $W$ bergantung pada laju kedatangan $\lambda$ dan laju pelayanan $\mu$. Oleh karena itu, dengan membuat nilai $W$ tetap, dapat ditentukan laju pelayanan $\mu$ berdasarkan laju kedatangan $\lambda$, yakni dengan formula

$$
\mu=\lambda+\frac{1}{W}
$$

\section{Contoh 2.}

Dari serangkaian pengamatan, diketahui bahwa rata-rata lama kunjungan wisatawan di tempat tersebut adalah 30 menit. Oleh karena itu, pada saat pengunjung datang mengikuti distribusi Poisson dengan laju sebesar 60 orang/jam atau 1 orang per menit $(\lambda=1)$, akan diperoleh laju kepulangan $\mu=1,033$ dan rata-rata banyaknya pengunjung dalam sistem sebesar 29 orang. Selanjutnya bila jumlah kunjungan meningkat hingga mencapai kedatangan 120 orang/jam $(\lambda=2)$, diperoleh laju kepulangan $\mu=2,033$. dan rata-rata banyaknya pengunjung dalam sistem berubah menjadi 50 orang.

Dapat dilihat bahwa contoh 2 lebih realistis dibanding contoh 1 karena laju kepulangan pengunjung juga dipengaruhi oleh laju kedatangannya. Semakin banyak pengunjung yang datang, semakin cepat pula pengunjung lainnya meninggalkan tempat wisata tersebut. Selain itu, jumlah pengunjung di tempat wisata tersebut terlihat lebih masuk akal, yakni antara 29 orang hingga 59 orang. Selanjutnya dari contoh tersebut dapat didefinisikan suatu model bagi pengunjung tempat wisata sebagai berikut.

Definisi 1. Model objek wisata sederhana merupakan modifikasi dari model antrian satu pelayan (singleserver queuing model) dengan dua parameter yakni laju kedatangan pengunjung dan rata-rata lama kunjungan.

Di bawah asumsi bahwa laju kedatangan pengunjung berdistribusi eksponensial dengan mean $1 / \lambda$ serta laju kepulangan responden berdistribusi eksponensial (yakni model antrian $\mathrm{M} / \mathrm{M} / 1$ ), hubungan antara laju kedatangan pengunjung, rata-rata lama kunjungan, dan rata-rata banyaknya pengunjung tempat wisata ditunjukkan pada Gambar 1. 


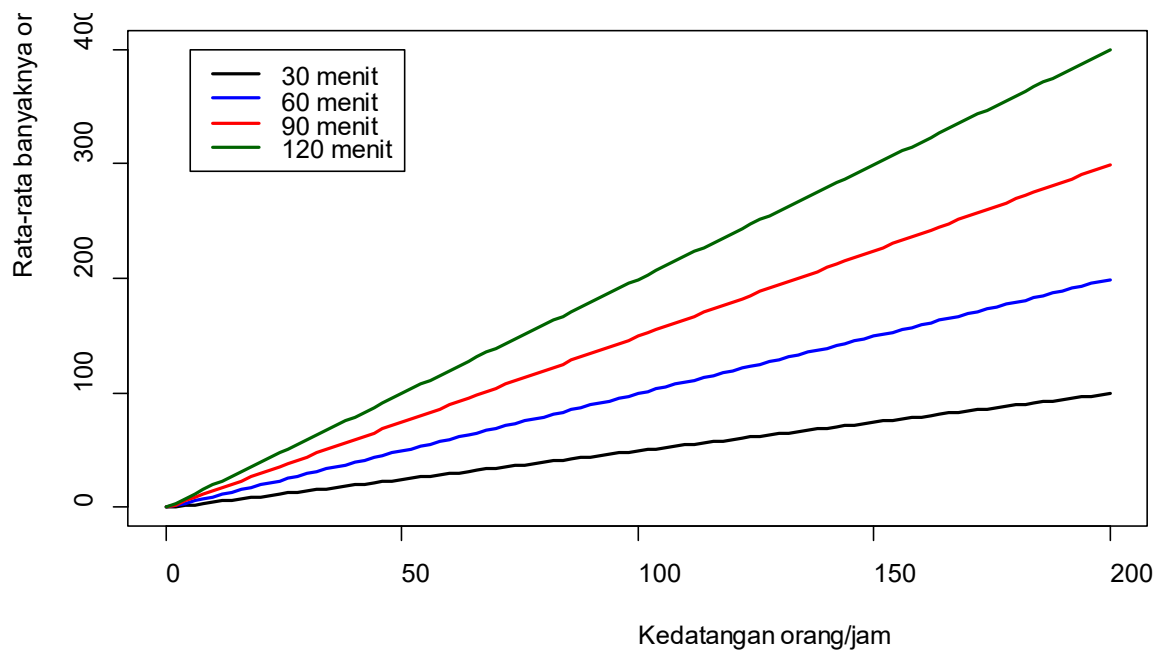

Gambar 2. Hubungan antara laju kedatangan pengunjung dan rata-rata banyaknya pengunjung pada beberapa durasi kunjungan di bawah asumsi model $\mathrm{M} / \mathrm{M} / 1$

Dari Gambar 2, terlihat hubungan antara jumlah kedatangan orang per jam terhadap rata-rata banyaknya pengunjung di dalam sistem, yakni di dalam objek wisata. Diperhatikan bahwa semakin lama pengunjung berada di tempat wisata tersebut, laju kedatangan orang yang sama akan menyebabkan rata-rata banyaknya orang yang lebih tinggi. Bila batas maksimum jumlah pengunjung di suatu tempat wisata adalah 200 orang, misalnya, maka kehadiran 100 orang dalam satu jam terakhir akan menyebabkan batas ini terpenuhi manakala rata-rata pengunjung menghabiskan waktu hingga dua jam di tempat tersebut.

Model di atas dapat dikembangkan lebih lanjut dengan meniadakan asumsi distribusi eksponensial pada waktu antar kepulangan pengunjung tempat wisata. Dengan demikian, didapat model M/G/1 yang dapat diselesaikan dengan formula Pollaczek-Khintchine (4) di muka. Selanjutnya diperhatikan bahwa pada model ini, terdapat sejumlah parameter yang digunakan yakni laju kedatangan $(\lambda)$, rata-rata laju pelayanan, dan variansi laju pelayanan. Hubungan antara ketiga parameter tersebut dinyatakan secara matematis oleh persamaan (4) dan ditunjukkan secara grafis pada gambar 3.
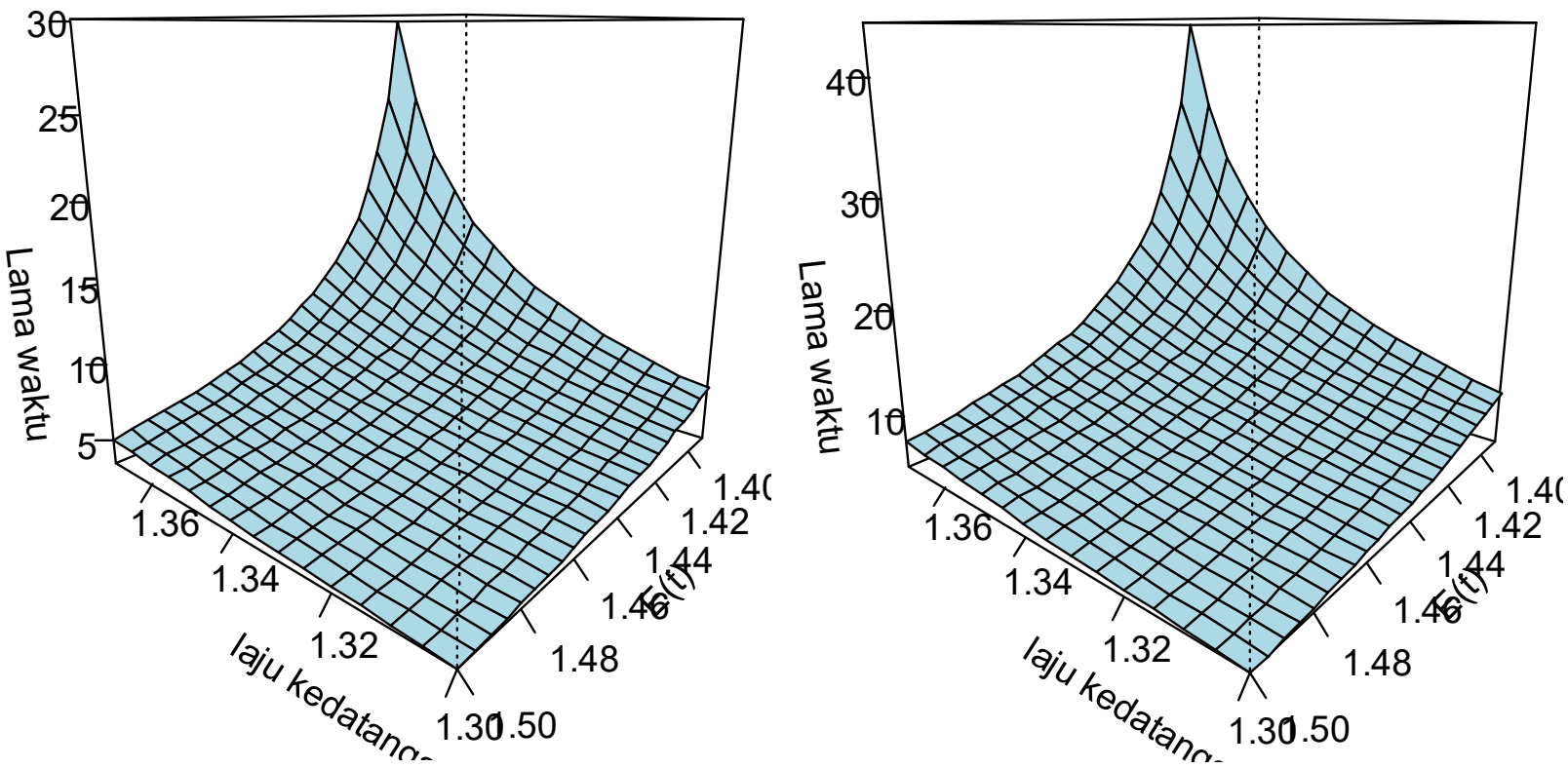

Gambar 3. Lama waktu tunggu (dalam menit) sebagai fungsi dari laju kedatangan dan rata-rata laju pelayanan, untuk nilai variansi laju pelayanan sebesar 0,1 (kiri) dan 0,4 (kanan).

Berdasarkan Gambar 3, dapat diketahui bahwa untuk laju kedatangan $\lambda=1.3$ (ekuivalen dengan 78 orang per menit) dan rata-rata laju pelayanan sebesar 1.4 (ekuivalen dengan 84 orang per menit) dengan variansi sebesar 0.1 (2,5 orang per menit), lama waktu yang diperlukan di dalam sistem adalah sekitar 10 menit. Dapat diketahui pula bahwa untuk nilai variansi laju pelayanan yang lebih tinggi, lama waktu tunggu akan semakin 
tinggi. Selisih antara laju kedatangan dan rata-rata laju kepulangan haruslah cukup kecil agar diperoleh lama waktu yang relatif 'wajar' untuk suatu kunjungan pada objek wisata.

Lebih lanjut, pada model M/G/1 tersebut, informasi mengenai hubungan antara laju kedatangan dan lama kunjungan dapat digunakan untuk mengestimasi banyaknya pengunjung objek wisata sebagaimana ditunjukkan pada Tabel 1. Pada Tabel 1 ini diasumsikan variansi laju pelayanan adalah sebesar 0,8 .

Tabel 1. Hubungan antara laju kedatangan, lama kunjungan, dan banyaknya pengunjung objek wisata dengan model $\mathrm{M} / \mathrm{G} / \mathbf{1}$

\begin{tabular}{ccccccc}
\hline Laju kedatangan (orang/jam) & 84 & 84 & 85 & 85 & 85 & 86 \\
\hline lama kunjungan (menit) & 60 & 190 & 50 & 60 & 100 & 50 \\
\hline Estimasi banyaknya pengunjung & 90 & 264 & 66 & 89 & 133 & 68 \\
\hline
\end{tabular}

Berdasarkan Tabel 1, terlihat bahwa untuk jumlah kunjungan sekitar 85 orang, rata-rata lama kunjungan sebesar 50 menit akan memberikan estimasi banyaknya pengunjung sebesar 66-68 orang. Bila kunjungan ditambah menjadi 60 menit, estimasi banyaknya pengunjung akan meningkat menjadi 89-90 orang. Lebih lanjut, bila kunjungan berlangsung sekitar 3 jam, banyaknya pengunjung di dalam sistem dapat mengalami peningkatan hingga mencapai 264 orang. Analisis lebih lanjut untuk melihat estimasi banyaknya pengunjung pada berbagai kombinasi laju kedatangan dan lama kunjungan dapat dilakukan menggunakan metode simulasi.

\subsection{Kelebihan dan Kelemahan Model}

Pada uraian di atas telah ditunjukkan bahwa model antrian dapat dipergunakan untuk memodelkan jumlah pengunjung objek wisata. Pemodelan dilakukan dengan membuat perbandingan atau analogi antara sistem antrian dan objek wisata, sebagaimana ditunjukkan pada Tabel 2, berikut:

Tabel 2. Komponen model antrian dan implementasinya pada pemodelan jumlah pengunjung objek wisata

\begin{tabular}{ll}
\multicolumn{1}{c}{$\begin{array}{c}\text { Komponen model antrian pada } \\
\text { umumnya }\end{array}$} & $\begin{array}{c}\text { Komponen model jumlah pengunjung } \\
\text { objek wisata }\end{array}$ \\
\hline Pelanggan & Pengunjung tempat wisata \\
\hline Pelayan (pemberian layanan) & $\begin{array}{l}\text { Proses pengunjung meninggalkan tempat } \\
\text { wisata }\end{array}$ \\
\hline Antrian & $\begin{array}{l}\text { Pengunjung yang sedang berada di tempat } \\
\text { wisata }\end{array}$ \\
\hline Laju kedatangan pelanggan & Laju kedatangan pengunjung \\
\hline Lama pelanggan di dalam sistem & $\begin{array}{l}\text { Lama pengunjung berada di tempat } \\
\text { wisata }\end{array}$ \\
\hline Banyaknya pelanggan di dalam sistem & \begin{tabular}{l} 
Banyaknya pengunjung di tempat wisata \\
\hline Laju pelayanan
\end{tabular} \\
$\begin{array}{l}\text { Laju pengunjung meninggalkan tempat } \\
\text { wisata }\end{array}$ \\
\hline
\end{tabular}

Uraian pada Tal ini disebabkan oleh tersedianya rumus-rumus eksplisit yang dapat dipergunakan untuk menentukan lama pelanggan beraa di dalam sistem dan banyaknya pelanggan di dalam sistem. Implementasi model $\mathrm{M} / \mathrm{M} / 1$ dan $\mathrm{M} / \mathrm{G} / 1$ menunjukkan bahwa model ini mengasumsikan bahwa pengunjung datang dan pergi secara satu per satu, tidak bersamaan dalam satu rombongan. Penelitian lanjutan dapat dilakukan untuk memperlunak asumsi ini dan menggunakan model-model distribusi lain, yakni dengan melakukan simulasi.

\section{KESIMPULAN}

Penelitian ini memberikan gambaran awal bahwa model antrian dapat dikembangkan untuk memodelkan jumlah pengunjung suatu objek wisata. Dalam model ini banyaknya pengunjung dipandang sebagai banyaknya unit yang berada di dalam sistem antrian, yang nilainya dipengaruhi oleh lama kunjungan dan laju kedatangan pengunjung. Adapun variabel lama kunjungan diatur dengan mengubah-ubah nilai laju pelayanan sebagai fungsi dari laju kedatangan, yakni dengan mengasumsikan bahwa semakin tinggi laju kedatangan, semakin tinggi pula laju pelayanan atau laju kepulangan pengunjung dari objek wisata tersebut. 


\section{DAFTAR PUSTAKA}

[1] L. R. Amir et al., "Student perspective of classroom and distance learning during COVID-19 pandemic in the undergraduate dental study program Universitas Indonesia," BMC Med. Educ., vol. 20, no. 1, pp. 1-8, 2020, doi: 10.1186/s12909-020-023120 .

[2] T. Moja, "National and institutional responses-reimagined operations-pandemic disruptions and academic continuity for a global university," Stud. High. Educ., vol. 46, no. 1, pp. 19-29, 2021, doi: 10.1080/03075079.2020.1859688.

[3] J. Jung, H. Horta, and G. A. Postiglione, "Living in uncertainty: the COVID-19 pandemic and higher education in Hong Kong," Stud. High. Educ., vol. 46, no. 1, pp. 107-120, 2021, doi: 10.1080/03075079.2020.1859685.

[4] M. Szmigiera, "Impact of the coronavirus pandemic on the global economy - Statistics \& Facts," Statista, 2021.

[5] N. G. Uğur and A. Akbıyık, "Impacts of COVID-19 on global tourism industry: A cross-regional comparison," Tour. Manag. Perspect., 2020, doi: 10.1016/j.tmp.2020.100744.

[6] D. Dinarto, A. Wanto, and L. C. Sebastian, “Global Health Security-COVID-19: Impact on Bintan's Tourism Sector,” RSIS Comment. 033-20, 2020.

[7] S. Gössling, D. Scott, and C. M. Hall, "Pandemics, tourism and global change: a rapid assessment of COVID-19," J. Sustain. Tour., 2020, doi: 10.1080/09669582.2020.1758708.

[8] M. E. Atmojo and H. D. Fridayani, “An Assessment of Covid-19 Pandemic Impact on Indonesian Tourism Sector," J. Gov. Public Policy, 2021, doi: 10.18196/jgpp.811338.

[9] Direktorat Analisis dan Pengembangan Statistik, Indikator Ekonomi Indikator Ekonomi. Jakarta: BPS RI.

[10] A. Maharani and F. Mahalika, "New Normal Tourism sebagai Pendukung Ketahanan Ekonomi Nasional pada Masa Pandemi," J. Kaji. LEMHANNAS RI, 2020.

[11] I. D. G. Sugihamretha, "Respon Kebijakan: Mitigasi Dampak Wabah Covid-19 Pada Sektor Pariwisata," J. Perenc. Pembang. Indones. J. Dev. Plan., 2020, doi: 10.36574/jpp.v4i2.113.

[12] T. Sheikh, S. K. Singh, and A. K. Kashyap, “A Study of Queuing Model for Banking System,” Int. J. Ind. Eng. Technol., 2013.

[13] A. A. Onoja, O. L. Babasola, E. Moyo, and V. Ojiambo, "The Application of Queuing Analysis in modeling Optimal Service level,” Int. J. Sci. Eng. Res., 2018, doi: 10.14299/ijser.2018.01.002.

[14] M. E. Zonderland and R. J. Boucherie, "Queuing networks in healthcare systems," in International Series in Operations Research and Management Science, 2012.

[15] Y. Ding, D. Gupta, and X. Tang, "Early Reservation for Follow-up Appointments in a Slotted-Service Queue," SSRN Electron. J., 2020, doi: $10.2139 / \mathrm{ssrn} .3616565$.

[16] S. N. Aulele, “Analisis sistem antrian pada Bank Mandiri cabang Ambon,” BAREKENG J. Ilmu Mat. dan Terap., 2014, doi: 10.30598/barekengvol8iss1pp45-49.

[17] H. MZ and I. Pratiwi, “Analisis sistem antrian dengan metode simulasi," J. Desiminasi Teknol., 2019.

[18] J. M. Smith, Introduction to Queueing Networks Theory Practice. 2018.

[19] U. N. Bhat, An Introduction to Queueing Theory: Modeling and Analysis in Applications. Birkhäuser Boston, 2008.

[20] S. Dewanto and A. Santosa, "Simulasi Sistem Pelayanan Rawat Jalan di Rumah Sakit Menggunakan Simulasi Kejadian Diskrit," Ina. J. Ind. Qual. Eng., 2020, doi: 10.34010/iqe.v8i1.2725.

[21] Taha, H.A., Operations Research, $10^{\text {th }}$ edition. 2017. 